\title{
Olfactory system damage in rats and emotional, muricidal, and rat pup killing behavior*
}

\author{
B. MICHAEL THORNE $\dagger$, MICHAEL AARON, and EDWARD E. LATHAM \\ Mississippi State University, Mississippi State, Mississippi 39762
}

\begin{abstract}
Long-Evans female rats were subjected to a variety of olfactory-system lesions and compared with septally damaged and operated-control Ss in terms of handling characteristics, muricidal behavior, and behavior toward rat pups. Damage to the olfactory bulb rostral to the frontal poles resulted in increased mouse killing without changes in E-directed behavior. Additional damage under the frontal lobes increased both emotional behavior and mouse killing. Olfactory tubercle damage unaccompanied by olfactory bulb removal failed to produce either increased emotionality or mouse killing. A trend toward an increase in rat pup killing was noted in rats sustaining olfactory bulb damage. Finally, rats with septal damage, although extremely difficult to handle, did not display increased muricidal behavior.
\end{abstract}

Following a report by Douglas, Isaacson, and Moss (1969), many studies have appeared which dealt either directly or indirectly with a hyperemotionality syndrome in rats subjected to olfactory bulb (OB) removal (e.g., Malick, 1970; Seago, Ludvigson, \& Remley, 1970; Sieck \& Gordon, 1972). However, Es reporting an increase in emotionality in bulbectomized rats have always admitted that some animals were indistinguishable from normals (e.g., Douglas et al, Seago et al). Indeed, several reports have been published recently of studies in which little or no change in emotionality was found in bulbectomized rats (e.g., Bandler \& Chi, 1972; Phillips, 1970; Thorne, Aaron, \& Latham, 1973). Despite the obvious disagreement in the literature, the idea of an OB syndrome is widely accepted.

Previous reports by the present author and his associates (Thorne \& Linder, 1971; Thorne et al, 1973) have shown that neither the sex nor the strain of the animal determine the animal's behavior toward the $\mathrm{E}$ following OB damage. Another major variable, which has received little experimental attention, however, is the way in which the operation is performed.

That the surgical variable may be important in the appearance or nonappearance of the $\mathrm{OB}$ syndrome is apparent from a critical reading of the description of surgery in previous studies. For example, of the studies in which hyperemotionality was not observed, Phillips (1970), Thorne and Linder (1971), and Thorne et al (1973) removed essentially all bulb tissue rostral to the frontal poles without damaging any olfactory tissue underlying the frontal poles. By contrast, Douglas et al (1969) used the de Groot stereotaxic position in performing OB removals and thus destroyed additional olfactory material under the frontal poles. Similarly,

* The research was in part supported by an institutional grant from NSF awarded to Mississippi State University.

$\lceil$ Requests for reprints should be sent to B. Michael Thorne, Department of Psychology, P.O. Drawer PF, Mississippi State, Mississippi 39762
Seago et al (1970) reported the removal of both the olfactory bulbs and connecting tracts. Since both Douglas et al and Seago et al reported hyperemotionality, extent of removal may be important for production of the syndrome. Parenthetically, the amount of $\mathrm{OB}$ sparing rostral to the poles may also be relevant, since Bandler and Chi (1972) found that partial lesions facilitated intermale aggression although E-directed aggression was unchanged.

Also of possible importance is the use or nonuse of Gelfoam in packing the cavity left after OB removal. For example, Spector and Hull (1972) found hyperemotionality in rats whose wounds had been packed with Gelfoam, while Phillips (1970) and Thorne et al (1973) did not use Gelfoam and did not find increased emotionality.

Finally, a recent study by Sieck (1973) has reported that lesions destroying varying amounts of the olfactory system have differential effects upon emotionality. Specifically, minimal damage produced less reactive animals than did more complete removal of the $\mathrm{OB}$, and damage ventral to the frontal poles resulted in the most reactive Ss. Although conflicting statements were made in the paper, all brain-damaged Ss were reported to be more difficult to handle than operated-control animals, a result which disagrees with other studies of the effects of OB damage.

The present study was designed to investigate systematically the effects upon emotionality in rats of the production of several different types of OB lesions. Specifically, surgical techniques were chosen to replicate as closely as possible the methods employed in OB removal in studies reporting hyperemotionality and also in those in which hyperemotionality was not found. Thus, the following groups were compared: operated-control animals, animals with partial ablations, animals with both $\mathrm{OB}$ damage and the application of Gelfoam, animals with OB removal plus damage ventral to the frontal poles. Additional groups for comparison 

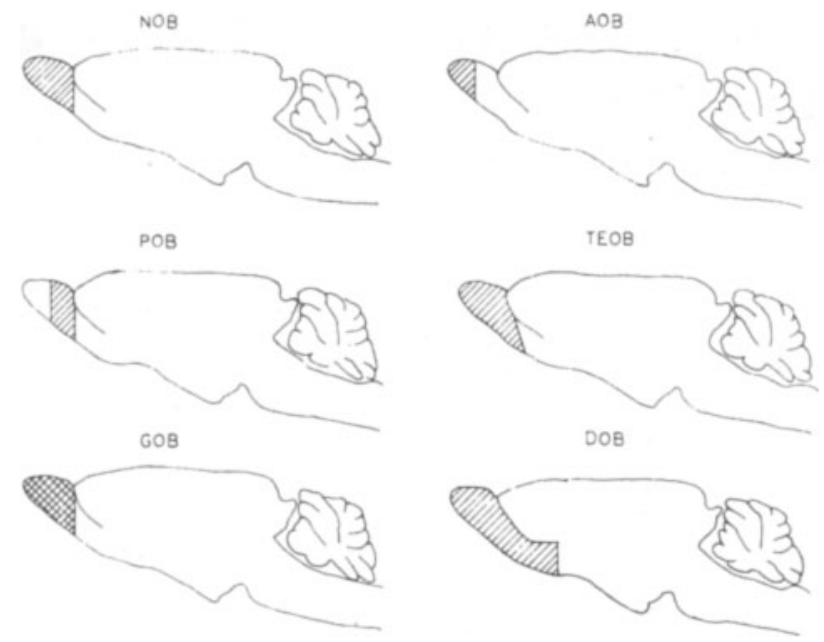

Fig. 1. Intended damage for each OB group. Shaded area represents the intended extent of destruction. Crosshatching in Group GOB indicates the addition of Gelfoam.

included rats sustaining septal damage and animals with lesions to the olfactory tubercles. A rating scale was used to evaluate differences in emotionality, while a muricidal test was given in order to measure differences in predatory aggression. Additionally, some animals from each group were exposed to rat pups following the muricidal test as a measure of intraspecific aggression.

\section{METHOD}

\section{Subjects}

The Ss were 120 adult female Long-Evans rats. Breeding stock of the rats was obtained from Research Animals, Inc. (Braddock, Pennsylvania), and most of the animals used in the study came from this stock. However, in order to complete the study, additional animals were purchased from the original supplier and assigned randomly to the experimental groups.

Animals were housed in group cages until approximately $24 \mathrm{~h}$ prior to surgery, at which time they were singly housed in hanging cages measuring $17.78 \times 25.40 \times 17.78 \mathrm{~cm}$. The animals were maintained under constant food and water conditions and were not gentled prior to surgery.

At the time of surgery, the mean weight of all animals included in the data analysis was $240 \mathrm{~g}$. There were no significant differences in the preoperative weights between groups. Although age records were not kept, all rats were more than 60 days old at the time of surgery.

The rats were assigned randomly to the following surgical groups: operated-control (OC), normal olfactory bulb removal (NOB), anterior olfactory bulb removal (AOB), posterior olfactory bulb removal (POB), NOB plus Gelfoam (GOB), elevated toothbar bulbectomy (TEOB), damage to the olfactory system underlying the frontal neocortex (DOB), damage to the olfactory tubercles (OT), and septal damage (SEP). Because of either postoperative illness, death, or inaccurate placement of the lesion, $26 \mathrm{Ss}$ were discarded, leaving a total $\mathrm{N}$ of 94 with the following distribution: $\mathrm{OC}, \mathrm{NOB}, \mathrm{AOB}, \mathrm{POB}, \mathrm{TEOB}, 10 \mathrm{Ss}$ per group; GOB, DOB, $11 \mathrm{Ss}$ per group; SEP, $9 \mathrm{Ss}$; OT, $13 \mathrm{Ss}$. Of the 26 Ss omitted, 18 were discarded because of either illness or death, while $1 \mathrm{~S}$ from Group SEP had a lesion failing to damage the septal area and 7 OT Ss received damage that was undetectable upon gross inspection.

\section{Surgery and Histology}

The Ss were anesthetized with chloral hydrate, approximately
$75 \mathrm{mg}$ per animal, injected IP. Their heads were then clipped and a small cut was made below each ear to expose the external auditory meatus prior to being secured in the headholder of a Baltimore stereotaxic instrument. For all animals except Ss in Groups TEOB and OT, the dorsal surface of the skull was horizontal with respect to the base of the headholder. The toothbar was elevated $5 \mathrm{~mm}$ above the level of the earbars for Ss in Groups OT and TEOB.

For all bulbectomized groups, a section of bone overlying the bulbs and frontal poles was removed by means of a dental drill and mastoid rongeurs. A cut with a No. 11 scalpel blade was then made immediately rostral to the frontal poles and perpendicular to the base of the headholder in animals assigned to Groups NOB, TEOB, GOB, and DOB. All bulb tissue anterior to the cut was removed by aspiration. Additional olfactory system tissue underlying the poles was aspirated in Ss assigned to Group DOB. For the rats in Group GOB, the cavity left after removal of the olfactory bulbs was packed with a piece of Gelfoam measuring approximately $20 \times 20 \times 7 \mathrm{~mm}$. The Ss in Group $O C$ received the same operative procedure except that no brain tissue was damaged.

The Ss in Groups AOB and POB received partial OB damage rostral to the frontal poles, with the anterior half removed in Group AOB and the posterior half in Group POB. In each case, a knife cut or cuts were first made and then the appropriate tissue removed by aspiration.

Both the septal Ss and animals in Group OT received electroly tic damage. The septal area was destroyed by passing $\mathrm{dc}$ ( $2 \mathrm{~mA}$ ) for $20 \mathrm{sec}$ through a stainless steel electrode with $1 \mathrm{~mm}$ of the tip uninsulated. The coordinates employed were $0.5 \mathrm{~mm}$ anterior to bregma, $0.5 \mathrm{~mm}$ lateral to the midline, and $5.5 \mathrm{~mm}$ ventral to the cortical surface. Damage to the olfactory tubercle was effected by two electrode placements on each side of the midline. The coordinates employed for half of the S's were $4.0 \mathrm{~mm}$ anterior to bregma, $2.0 \mathrm{~mm}$ lateral, $8.5 \mathrm{~mm}$ ventral, and $3.0 \mathrm{~mm}$ anterior, $2.5 \mathrm{~mm}$ lateral, $9.5 \mathrm{~mm}$ ventral, while the remainder received lesions at $5.0 \mathrm{~mm}$ anterior, $1.5 \mathrm{~mm}$ lateral, $7.5 \mathrm{~mm}$ ventral, and $4.0 \mathrm{~mm}$ anterior, $2.0 \mathrm{~mm}$ lateral, and $8.5 \mathrm{~mm}$ ventral. Current employed at each placement for the tubercle lesions was $0.8-1.0 \mathrm{~mA}$ for $5-10 \mathrm{sec}$. The intended extent of damage for each OB group is shown in Fig. 1.

Following the completion of testing, all operated animals were sacrified, the top of the skulls removed, and the heads placed in a $10 \%$ Formalin solution for at least 1 week prior to extraction of the brains. The lesions of bulbectomized animals were reconstructed on line drawings of the dorsal surface of a rat brain and an estimate made of the extent of damage rostral to the frontal poles, using the method described by Thorne et al (1973). Additionally, in bulbectomized animals with destruction extending under the poles and also in Ss from Groups SEP and OT, sections were made at 100 microns with a freezing microtome. Unstained sections through the damaged area were placed on slides and photographed after enlargement (see Thompson, 1971, for additional details).

\section{Emotionality Rating}

All animals were rated for emotionality once daily on the first 4 postoperative days on a five-component rating scale modified from King (1958). The components were as follows: reaction to presentation of a pencil to the perioral region of the animal, reaction to pencil tap on the side, ease of capture from the home cage, resistance to handling, and amount of vocalization during handling. Each component was rated on a 4-point scale (0-3), and each animal was given a daily total based upon the sum of the ratings of the five components. A bolus count was made at the end of the testing session and was treated as a separate measure of emotionality.

Immediately prior to testing, a clipboard was placed over the top of the S's home cage as it was being removed from the cage rack. This procedure was followed because septal animals in particular have a tendency to leap from an opened cage. The cage and clipboard were then carried to a metal table. The first 
Fig. 2. Unstained sections from a representative brain in Group DOB. Sections A-D depict successively more caudal damage.

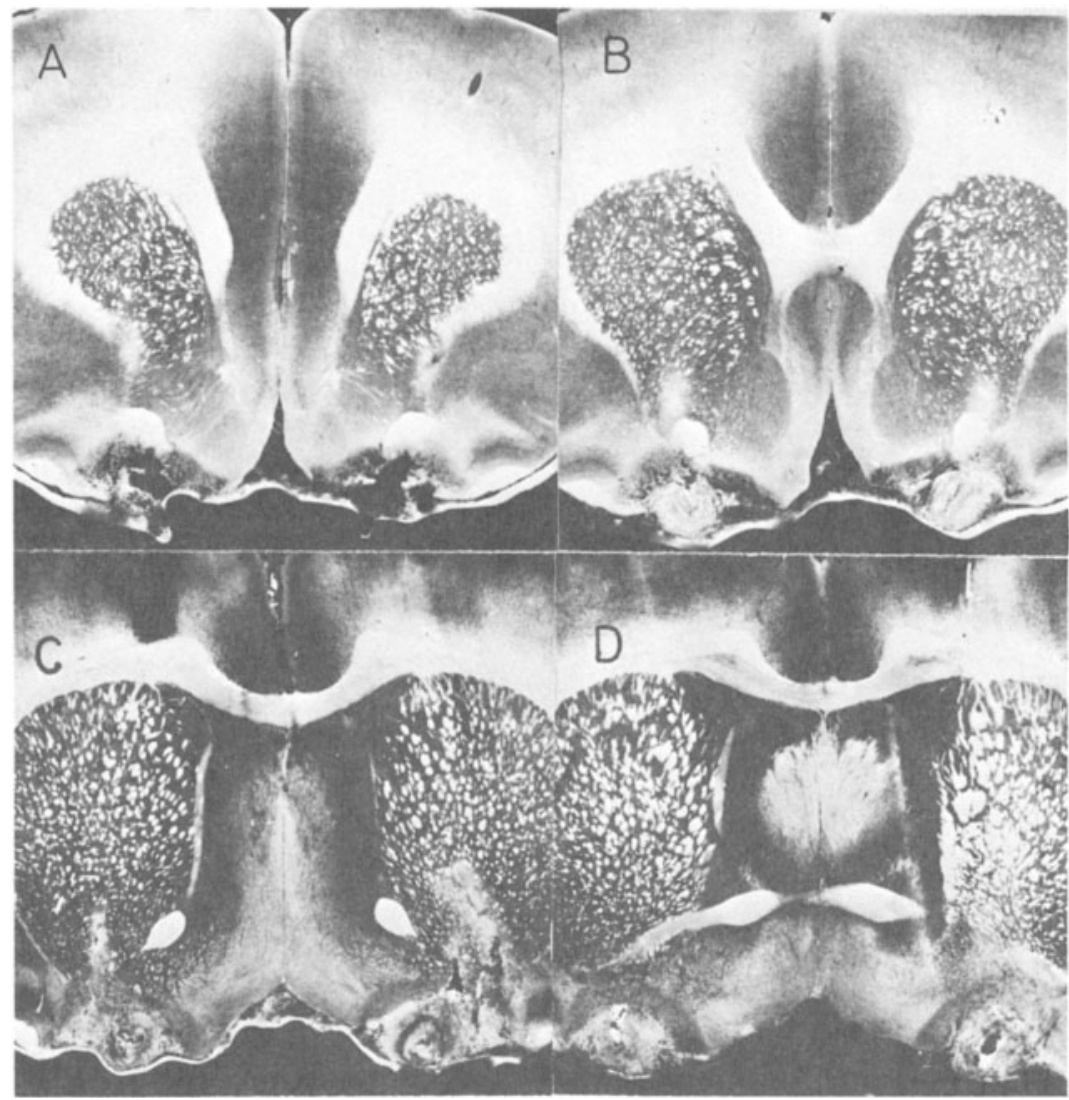

three components of the rating scale were scored with the animal in its cage (assuming it did not jump out after removal of the clipboard), while resistance to handling was rated with the animal on a gloved hand about $60 \mathrm{~cm}$ over its cage. Vocalization was rated throughout the testing session, which lasted approximately $1 \mathrm{~min}$. The five components were rated in the order listed, and testing occurred during the light portion of the rats' light-dark cycle.

In order to control for possible $\mathrm{E}$ bias in rating the animals, a single-blind testing procedure was employed in which the tester was unaware of the type of operation received by the animals he was testing. Additionally, frequent reliability sessions were employed, in which two independent Os rated the same animals. A correlation coefficient based upon the scores from the inter-O reliability checks was found to be $r=0.95$. The order of testing of the animals was varied daily to prevent any $S$ from being consistently influenced by the emotionality of a previous animal.

\section{Muricidal and Rat Pup Killing Tests}

On the 5 th postoperative day, an adult albino mouse was placed into the home cage of each $S$. The rat's reaction to the mouse was observed for the first $10 \mathrm{~min}$ after its introduction, and informal notes were made during this period. At the end of $24 \mathrm{~h}$, the mouse was removed and its general condition noted.

On the day following the muricidal test, approximately half of the Ss in each group were exposed to a rat pup (16-19 days old). Testing of the rat's reaction to the pup was identical to that employed in the test for muricide.

\section{RESULTS}

\section{Histology}

In terms of $\mathrm{OB}$ damage rostral to the frontal poles, the groups received approximately the following amounts of destruction: NOB, 88.8\%; AOB, 76.2\%; POB, 96.6\%; GOB, 99.6\%; DOB, 99.6\%; TEOB, $100 \%$. Comparison of the groups revealed that differences among them were significant $(F=18.46, d f=5 / 56$, $\mathrm{p}<.01)$. Using the Scheffé test, it was found that Group AOB sustained less damage than any other group ( $p<.01$ for all comparisons except AOB-NOB, $p<.05$ ) and that Group NOB had less OB removal rostral to the frontal poles than Group TEOB $(p<.05)$, but did not differ significantly from Groups POB, GOB, or DOB.

Despite the attempt to spare the anterior half of the OB rostral to the frontal poles in Group POB animals, in only one case was there any normal-appearing bulb tissue present when the brain was removed from the skull. Thus, the animals in this group received essentially complete removal of the $\mathrm{OB}$, although this was not intended.

In general, $S s$ in Group GOB suffered greater destruction than intended, with most having both bilateral damage to frontal cortex and damage to the olfactory system underlying the frontal poles. The posterior boundary for damage ventral to the frontal area in Group GOB ranged from approximately 6 to $3 \mathrm{~mm}$ anterior to bregma, as determined by comparison with the atlases of Skinner (1971) and Pellegrino and Cushman (1967). Thus, in some cases, animals in this group received damage to the nucleus accumbens, 


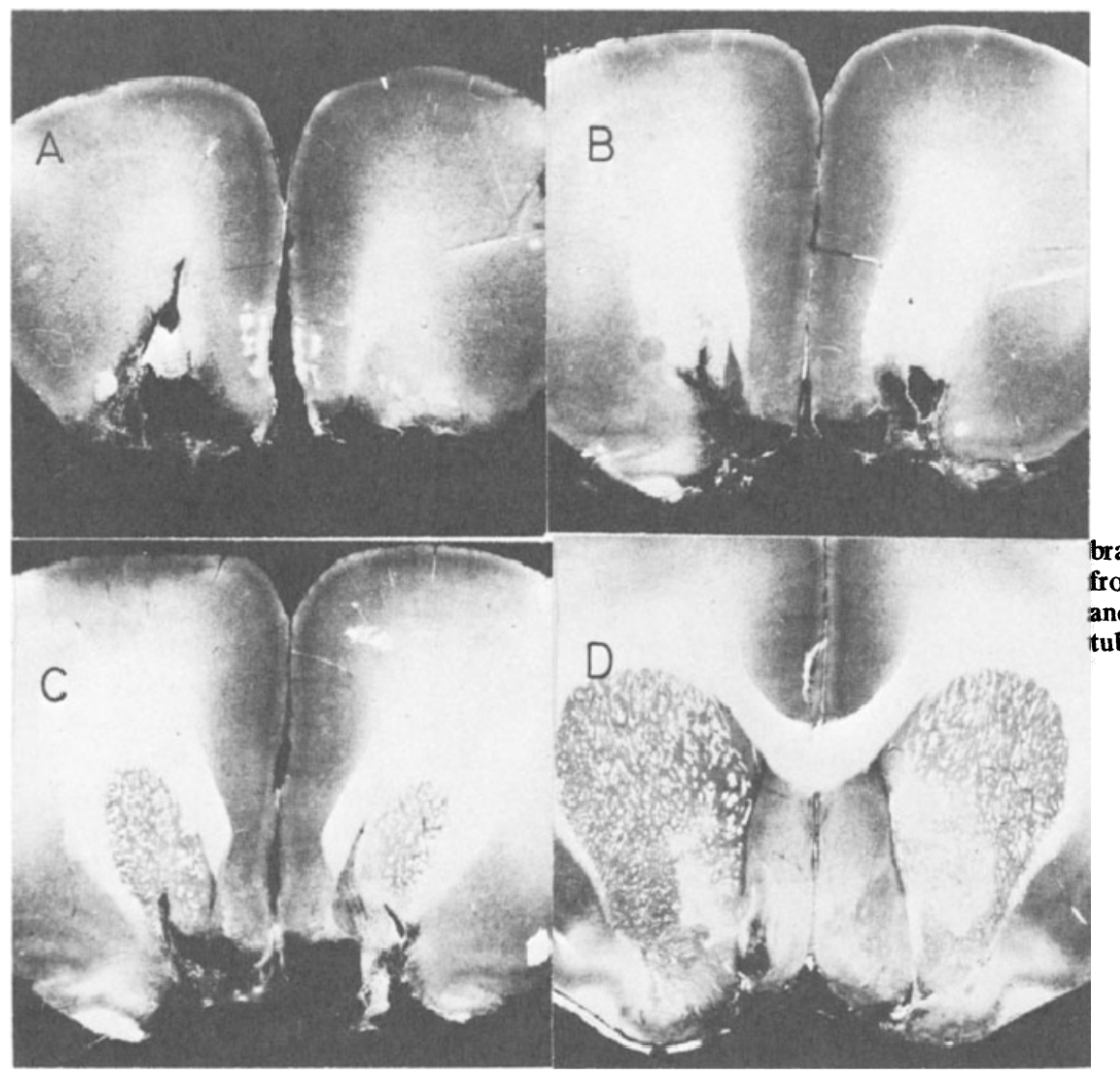

Fig. 3. Unstained sections from two brains in Group OT. Sections $A$ and B are from an anterior lesion, while Sections C and $D$ are from a posterior olfactory tubercle lesion.

nucleus caudatus putamen, medial forebrain bundle (MFB), anterior commissure, and the olfactory tubercle. Additionally, most Ss sustained damage to the rostral extension of the anterior olfactory nucleus. In contrast, only two animals in Group NOB suffered any damage ventral to the frontal poles, and in both cases it was unilateral. The extra damage in Group GOB is possibly attributable to pressure from the Gelfoam used to pack the wound.

With the exception of two rats, all animals in Group DOB received extensive damage ventral to the frontal poles, with four suffering some damage to frontal neocortex as well. The posterior boundary for the ventral damage ranged from approximately 3 to $2 \mathrm{~mm}$ anterior to bregma and thus ex tended considerably more caudally than did damage in Group GOB. In addition to receiving damage to the structures listed for Group GOB, lesions in this group involved the tract of the diagonal band of Broca and the lateral olfactory tract (unilateral destruction in some cases). A representative lesion may be found in Fig. 2.

In addition to receiving virtually complete destruction of the OB rostral to the frontal poles, all Ss from Group TEOB except one received damage ventral to the frontal poles. In six cases, this damage was bilateral, and in five, it extended caudally to approximately $6 \mathrm{~mm}$ anterior to bregma. Thus, most of the Ss in this group received lesions that were very similar to those sustained by some of the Group GOB Ss.
The $13 \mathrm{Ss}$ in Group OT were divided into two different, relatively homogeneous, groups on the basis of destruction of the olfactory tubercle. The larger group consisted of 10 animals with damage falling within the region of approximately $4-5 \mathrm{~mm}$ anterior to bregma. Within this area, the lesions were very restricted in locus, with most animals receiving damage to the olfactory tubercle almost exclusively. Structures sustaining minor damage in some animals included the MFB, tract of the diagonal band of Broca, anterior commissure, anterior olfactory nucleus (unilateral damage in one $S$ ), nucleus accumbens, and putamen. A representative lesion may be seen in Fig. 3.

The remaining Ss in Group OT suffered more caudal damage than that of the previous animals, ranging from approximately 2.5 to $0.5 \mathrm{~mm}$ anterior to bregma. Within these boundaries, there was some damage to the posterior portion of the olfactory tubercle and minor damage to surrounding structures, including the anterior amygdala, anterior preoptic nucleus, MFB, anterior commissure, and the nucleus preopticus magnocellularis. Sections from a representative $\mathrm{S}$ are shown in Fig. 3 .

The damage sustained by rats in Group SEP was in general very extensive. At the level of maximal destruction, the lesion typically extended from the ventral margin of the corpus callosum (which was damaged in several Ss) to the base of the brain. In addition to massive necrosis of the medial and lateral septal nuclei, other structures destroyed or receiving 
damage included the tractus diagonalis, anterior commissure, and the preoptic nucleus. A sample lesion from this group is shown in Fig. 4.

Within each $O B$ group, with the exception of Group POB, the animals were ranked in terms of the amount of damage to the olfactory system and frontal cortex, and the correlation between this ranking and the 4-day emotionality scores was obtained. Group POB Ss could not be ranked because of the lack of variability in the extent of damage. The only significant correlation obtained was in Group DOB $\left(\mathrm{r}_{\mathrm{s}}=0.74, \mathrm{p}<.01\right)$. Thus, in this group, greater emotionality was associated with more extensive damage.

A ranking was also made of all OB Ss except those in Group POB in terms of the amount of brain damage suffered by each, and the correlation between this ranking and the 4-day emotionality scores was calculated. Again, the degree of emotionality exhibited was related to the extent of damage $\left(r_{s}=.53, p<.01\right)$.

\section{Emotionality}

In general, damage to the $\mathrm{OB}$ rostral to the frontal poles did not have an effect upon emotionality. Nonparametric comparison of the total 4-day emotionality scores in each group revealed that Groups NOB, AOB, POB, and GOB did not differ significantly from Group $O C$ or from each other.

Removal of the olfactory bulbs plus damage ventral to the frontal poles (Groups DOB and TEOB) did result in emotionality increases, however. Mann-Whitney comparisons revealed that animals in Group DOB were significantly more emotional than Ss in Groups $\mathrm{OC}$ and AOB ( $p<.002$, two-tailed test) and in Groups NOB, POB, GOB, and OT $(\mathrm{p}<.02)$. Similarly, Ss in Group TEOB were more emotional than Ss in Groups OC, NOB, and POB $(p<.002)$; in Groups GOB and AOB $(p<.02)$; and in Group OT $(p<.05)$. The difference between Groups DOB and TEOB was not significant.

Despite increases in emotionality in some of the bulbectomized groups (DOB and TEOB), animals sustaining septal damage, as a group, displayed greater emotionality than any other animals. Specifically, Mann-Whitney comparisons resulted in significant differences, with $\mathrm{p}<.002$ in all cases except Group DOB $(p<.05)$. In fact, of the 85 Ss in the study subjected to nonseptal damage, only 8 had 4-day emotionality scores within the range of the septals. Of these 8 animals, 6 were Ss from Group DOB while 1 was from Group GOB and the other from Group TEOB.

As a group, OT Ss were more emotional than Group OC Ss $(p<.05)$; they were not significantly different from Ss in Groups NOB, AOB, POB, and GOB, and were significantly less emotional than animals in Groups DOB, TEOB, and SEP. Looking at individual scores, however, it is apparent that only 4 of 13 rats in this group had 4-day scores outside the range of the operated controls. Of these 4,3 were animals receiving

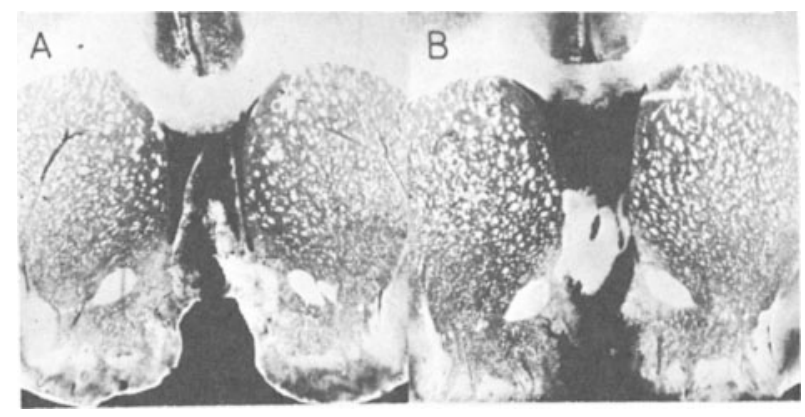

Fig. 4. Unstained sections from an animal in Group SEP.

posterior damage to the olfactory tubercle, and if these 3 are omitted from the comparison with Group OC, the two groups do not differ.

Although the average 4-day emotionality ratings were low for all bulbectomized groups except DOB and TEOB (see Table 1), it is possible that first-day scores were higher than similar scores of $\mathrm{OC}$ animals and that more rapid habituation in the $\mathrm{OB}$ animals masked this difference. In order to assess habituation, a comparison was made between the number of rats in each group whose 4th-day score was lower than the 1st-day score and the number whose scores either increased or did not change. By this measure, the group showing the most evidence for habituation (AOB) did not differ significantly from the controls (Fisher exact probability test, $p=.07)$. It is probable, of course, that a more lengthy testing period would result in greater evidence for habituation, but it seems clear that more rapid habituation did not account for the failure to obtain significant differences between Groups OC, NOB, AOB, POB, and GOB.

The counting of boluses as a measure of emotionality failed to differentiate between groups. The average 4-day bolus count per group is shown in Table 1 .

\section{Muricide and Rat Pup Killing}

The percentage of animals in each group that killed mice and rat pups is shown in Fig. 5. From this figure, it is evident that $\mathrm{OB}$ damage increased the probability that a rat would kill mice upon first exposure. Overall, 63\% of the bulbectomized Ss killed mice compared to $10 \%$ of the controls (Fisher exact probability test, $p=.002$ ), to $22 \%$ of the septals $(p=.02)$, or to $8 \%$ of the Ss in Group OT $\left(\chi^{2}=12.08, p<.001\right)$.

Looking at comparisons between individual groups, it was found that Groups AOB, POB, SEP, and OT did not differ significantly from Group OC or from each other. When compared with the OC Ss, animals in Groups NOB (Fisher test, $p<.005)$, GOB ( $p<.05)$, DOB $(p<.005)$, and TEOB $(p<.01)$ killed more mice. Further, both NOB and DOB rats killed more mice than either SEP or OT animals $(p<.005$, except for the NOB-SEP comparison, $p<.025)$. Additionally, both GOB 


\begin{tabular}{|c|c|c|c|c|}
\hline \multicolumn{5}{|c|}{$\begin{array}{l}\text { Mean 4-Day Emotionality Scores and } \\
\text { Mean Bolus Count Per Group }\end{array}$} \\
\hline Groups & $\mathrm{N}$ & \multicolumn{2}{|c|}{$\begin{array}{c}\text { Mean 4-Day Emo- } \\
\text { tionality Scores } \\
\text { (Range in Parentheses) }\end{array}$} & $\begin{array}{l}\text { Mean } \\
\text { Bolus } \\
\text { Count }\end{array}$ \\
\hline OC & 10 & 4.9 & $(1-14)$ & 4.0 \\
\hline NOB & 10 & 5.2 & $(0-13)$ & 5.4 \\
\hline $\mathrm{AOB}$ & 10 & 8.0 & $(2-26)$ & 6.9 \\
\hline POB & 10 & 6.1 & $(0-20)$ & 4.7 \\
\hline GOB & 11 & 10.4 & $(2-35)$ & 4.2 \\
\hline DOB & 11 & 25.6 & $(3-51)$ & 5.4 \\
\hline TEOB & 10 & 19.7 & $(8-32)$ & 6.0 \\
\hline SEP & 9 & 39.0 & $(27-58)$ & 3.9 \\
\hline OT & 13 & 10.8 & $(2-25)$ & 7.8 \\
\hline
\end{tabular}

$(p<.025)$ and TEOB $(p<.005)$ animals exhibited more muricide than Ss in Group OT. Finally, more DOB animals killed mice than rats in Groups $A O B$ and $P O B$ $(p<.025)$.

For the rat pup killing tests, 6 animals from each group were tested, with the exception of the following groups: POB, 5; TEOB, 7; SEP, 3. Removal of the olfactory bulbs resulted in a trend toward increased rat pup killing when all $\mathrm{OB}$ animals were compared with $\mathrm{OC}$ rats (Fisher exact probability test, $p=.07$ ). Of the 26 mouse killers tested with rat pups, 15 , or $58 \%$, killed the pup. Only $1 \mathrm{~S}$ killed a rat pup without having previously killed a mouse, an animal with septal damage. In this particular case, the rat began to vigorously groom the pup. As the pup began to squeal, the grooming intensified and became an attack ending in the pup's death.

When it occurred during the observation period, killing of both mice and rat pups was generally not affective in nature and usually involved bites to the head, neck, and back region of the victim. The killing usually occurred quickly once an attack had begun and was followed by almost total consumption of the body in the great majority of cases. Of the Ss killing both mice

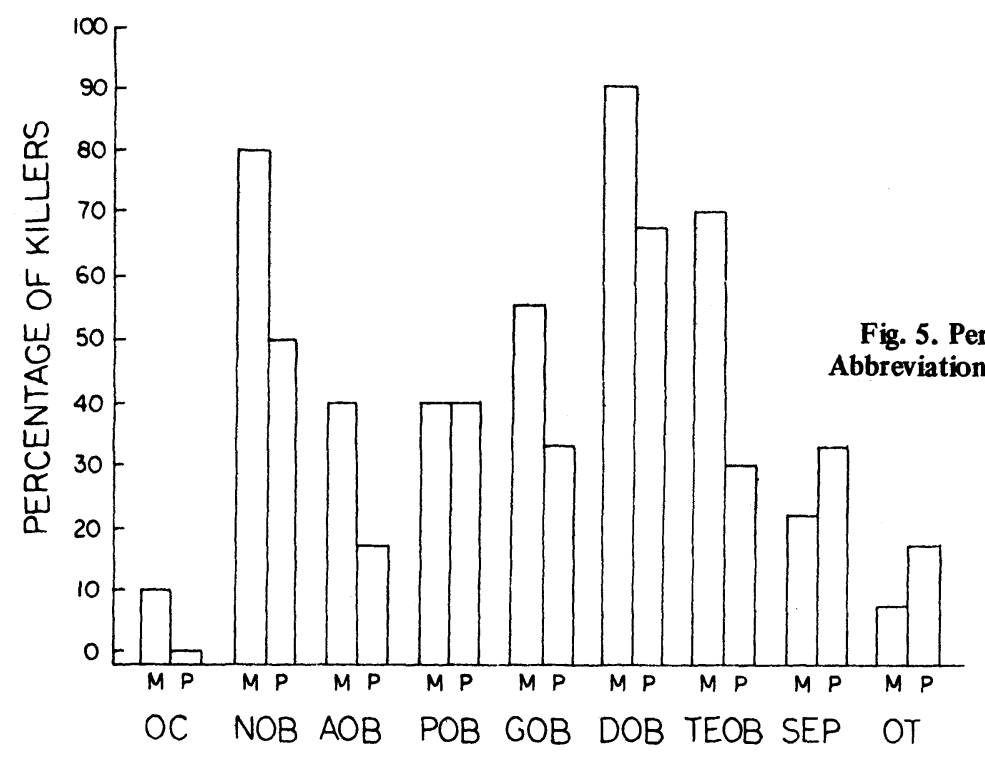

and rat pups, most killed the pup with a shorter latency than they they did the mouse. However, this observation is confounded by the fact that all of these animals had had killing experience and would be expected to kill sooner.

\section{DISCUSSION}

The results of the present experiment agree with previous work in finding that removal of the OB rostral to the frontal poles has little or no effect upon the handling characteristics of rats (Bandler \& Chi, 1972; Phillips, 1970; Thorne et al, 1973; Thorne \& Linder, 1971). However, by finding an increase in emotionality following OB removal plus damage ventral to the frontal poles, the present study both agrees with prior studies reporting increased emotionality (e.g., Douglas et al, 1969; Malick, 1970; Seago et al, 1970) and possibly explains previous failures to find changes.

Despite the possible generality of the present results, the work of Sieck (1973) and Sieck and Gordon (1972) cannot be explained in terms of our findings. Specifically, Sieck and his coworkers have found increased emotionality in rats with partial $O B$ damage as well as in animals with complete ablations rostral to the frontal poles. However, in accord with the present results, Sieck has found a relationship between the extent of rostral olfactory system damage and emotionality.

The finding that muricidal behavior is increased by OB damage agrees with previous research (Bandler \& Chi, 1972; Malick, 1970; Thorne et al, 1973). However, it is clear that the increased muricide is separable from increased emotionality as measured by handling characteristics. Thus, animals in some OB groups (NOB, GOB) exhibited an increase in mouse killing without differing from the controls in terms of emotionality. Septal animals, on the other hand, showed extreme
Fig. 5. Percentage of mouse and rat pup killers in each group. Abbreviations: $M=$ mice, $P=$ rat pups. 
changes in handling characteristics without an increase in mouse killing.

There are at least two possible interpretations for the trend toward increased rat pup killing seen in the bulbectomized Ss. One is that OB ablations result in a failure to differentiate between mice and rat pups (Myer, 1964). Secondly, it has recently been shown that experience in mouse killing enhances the probability that rat pups will also be killed (Paul, Miley, \& Mazzagatti, 1973). Conversely, experience in nonkilling increases the probability that animals will not kill on subsequent tests. This formulation would be directly applicable to the present results, since the muricidal test always preceded the test with rat pups. Of course, the two possible interpretations are not mutually exclusive and, indeed, may have been additive in the present case. Thus, OB damage increased the probability of mouse killing, which enhanced the likelihood that pups would be killed both because of a failure to differentiate and also because of selective experience with killing.

Although somewhat surprising, the failure of olfactory tubercle lesions to produce striking changes in emotionality was not totally unexpected, since at least one other $\mathrm{E}$ has obtained similar results (Hitt, personal communication, 1973). One possible explanation for the extreme emotionality exhibited by most animals in Group DOB would have to involve a mass action effect, with additional damage to the olfactory bulbs being necessary for the expression of hyperemotionality following olfactory tubercle damage. Another possibility, however, is suggested in a recent paper by Sieck and Gordon (1973), who found that damage to the lateral olfactory tract resulted in rats that were very hard to handle. In the present study, more DOB animals sustained lateral olfactory tract damage than did OT Ss.

In summary, the present data indicate that damage to the $\mathrm{OB}$ rostral to the frontal poles is unlikely to produce hyperemotionality, although muricidal behavior becomes more probable. Additional damage to the olfactory system underlying the frontal poles (anterior olfactory nucleus, lateral olfactory tract, olfactory tubercle) increases the probability of increased emotionality. This latter finding possibly provides an explanation for inconsistencies in the literature concerning the $\mathrm{OB}$ syndrome, i.e., either incidental or intentional damage under the frontal cortex resulted in increased emotionality or the lack of it resulted in failure to find such changes. It is felt that the study of more selective damage to the olfactory system accompanied by the use of careful testing procedures will eventually delineate the conditions necessary for the expression of emotionality after olfactory damage.

\section{REFERENCES}

Bandler, R. J., \& Chi, C. C. Effects of olfactory bulb removal on aggression: A reevaluation. Physiology \& Behavior, 1972, 8 , 207-211.

Douglas, R. J., Isaacson, R. L., \& Moss, R. L. Olfactory lesions, emotionality and activity. Physiology \& Behavior, 1969, 4, 379-381.

King, F, A. Effects of septal and amygdaloid lesions on emotional behavior and conditioned avoidance responses in the rat. Journal of Nervous \& Mental Disease, 1958, 126, 57-63.

Malick, J. B, A behavioral comparison of three lesion-induced models of aggression in the rat. Physiology \& Behavior, 1970, 5, 679-681.

Myer, J. S. Stimulus control of mouse-killing rats. Journal of Comparative \& Physiological Psychology, 1964, 58, 112-117.

Paul, L., Miley, W. M., \& Mazzagatti, N. Social facilitation and inhibition of hunger-induced killing by rats. Journal of Comparative \& Physiological Psychology, 1973, 84, 162-168.

Pellegrino, L. J., \& Cushman, A. J. A stereotaxic atlas of the rat brain. New York: Appleton-Century-Crofts, 1967.

Phillips, D. S. Effects of olfactory bulb ablation on visual discrimination. Physiology \& Behavior, 1970, 5, 13-15.

Seago, J. D., Ludvigson, H. W., \& Remley, N. R. Effects of anosmia on apparent double alternation in the rat. Journal of Comparative \& Physiological Psychology, 1970, 71, 435-442.

Sieck, M. H. Selective olfactory system lesions in rats and changes in appetitive and aversive behavior. Physiology \& Behavior, 1973, 10, 731-739.

Sieck, M. H., \& Gordon, B. L. Selective olfactory bulb lesions: Reactivity changes and avoidance learning in rats. Physiology \& Behavior, 1972, 9, 545-552.

Sieck, M. H., \& Gordon, B. L. Anterior olfactory nucleus or lateral olfactory tract destruction in rats and changes in appetitive and aversive behavior. Physiology \& Behavior, 1973, 10, 1051-1059.

Skinner, J. E. Neuroscience: A laboratory manual. Philadelphia: Saunders, 1971

Spector, S. A., \& Hull, E. M. Anosmia and mouse killing by rats: A nonolfactory role for the olfactory bulbs. Journal of Comparative \& Physiological Psychology, 1972, 80, 354-356.

Thompson, $R$. Introducing subcortical lesions by electrolytic methods. In R. D. Myers (Ed.), Methods in psychobiology. Vol. I. Laboratory techniques in neuropsychology and neurobiology. New York: Academic Press. Pp. 131-154.

Thorne, B. M., Aaron, M., \& Latham, E. E. Effects of olfactory bulb ablation upon emotionality and muricidal behavior in four rat strains. Journal of Comparative \& Physiological Psychology, 1973, 84, 339-344.

Thorne, B. M., \& Linder, L. H. No change in emotionality of rats following bulbectomy. Psychonomic Science, 1971, 24, 207-208.

(Received for publication December 17, 1973; accepted February 19, 1974.) 